\title{
Aproximaciones constructivistas a la Unión Europea*
}

\author{
Nicolás Mariscal \\ Profesor emérito de la Universidad de Deusto \\ Profesor Jean Monnet emérito
}

\begin{abstract}
Sumario: I. Introducción.-II. Los constructivismos en las Relaciones Internacionales: 1. Ontología; 2. Epistemología; 3. Metodología. III. El constructivismo social y su aplicación inicial a la Unión Europea: 1. The Social Construction of Europe; 2. El debate racionalismo-constructivismo. - IV. Tendiendo puentes entre constructivismos sociales. - V. Estudios empíricos sobre identidad(es) europea(s). - VI. Reintroduciendo el poder. - VII. Algunas reflexiones.
\end{abstract}

Resumen: Inicialmente se presenta el constructivismo en las Relaciones Internacionales. Frente al individualismo racionalista y el materialismo realista la alternativa constructivista es estructuralista e idealista; estructuras e ideas, agentes y estructuras se constituyen mutuamente. A continuación se centra el artículo en el constructivismo social aplicado a la Unión Europea, a la que llega en el último decenio del siglo Xx y produce más tarde vigorosos debates, que van perdiendo fuerza mientras se impone la conveniencia de tender puentes entre las variantes del constructivismo social, pero sin llegar a una «comunidad constructivista». Se exponen después algunos recientes estudios empíricos constructivistas sobre identidad(es) europea(s), así como intentos de reintroducir el poder en las aproximaciones constructivistas a la Unión Europea. Finalmente unas reflexiones cierran el artículo.

Palabras clave: Relaciones Internacionales, integración europea, constructivismo, agentes y estructuras, identidad(es) europea(s), poder y cultura.

Abstract: Constructivism in International Relations is introduced in the first place. Unlike rationalist individualism and realist materialism the constructivist alternative is structuralist and idealist in nature; structures and ideas, agents and structures are mutually constituted. Then the article focus on social constructivism applied to the European Union in the last decade of the twentieth century, later producing vigorous debates, which gradually lost strength as the desirability of bridging variants of social constructivism imposed itself, but without leading to a "constructivist community. Some recent empirical constructivist studies on European identity and attempts to reintroduce power in constructivist approaches to the European Union are then dealt with. Some final reflections close the article.

Keywords: International Relations, European integration, constructivism, agents and structures, European identity / identities, power and culture.

* Recibido el 20 de marzo de 2012, aceptado el 31 de mayo de 2012. 


\section{Introducción}

La Unión Europea está viviendo la crisis probablemente más grave desde su nacimiento en 1951. Los impresionante logros de los primeros cincuenta años en torno a la construcción de un mercado común, culminado con la introducción del euro y la ampliación de 6 a 27 Estados miembros, se estancaron, sin embargo, en el primer decenio del presente siglo XXI, una década perdida. Los europeos no hemos sido capaces de avanzar hacia una unión política, que tanto la propia dinámica comunitaria, como los retos de un mundo en proceso de globalización exigían. Recorrimos con éxito la estrategia de los «padres fundadores» del crecimiento sector por sector, de las realizaciones concretas, de la creación de solidaridades de hecho centrada en la construcción de un mercado común, pero olvidamos, preterimos sine die los pasos hacia el horizonte convenido de una federación europea. Hoy, en plena crisis, la echamos de menos, mientras se multiplican las voces reclamándola, aunque nadie sabe bien cómo hacerla realidad, ni todavía parece estar respaldada por poderosas fuerzas ni amplios sectores de la ciudadanía.

Para salir de la grave situación actual, la UE necesita reorientarse y movilizar todos sus recursos. Son muchos y muy poderosos. Uno relativamente modesto, pero cualitativamente importante, es el acervo teórico, el rico tesoro de ideas, reflexiones críticas y creativas, estudios empíricos y normativos acumulados a lo largo de la vida de la CE/UE. Es verdad que el curso de ésta ha sido muy pragmático y continuamente negociado, pero ha generado y ha contado también con el substrato de un elaborado acervo teórico comunitario. En situaciones dramáticas y encrucijadas existenciales como las que la UE está experimentando no parece sensato olvidarlo y él, por su parte, debe contribuir con nuevos aportes a iluminar el camino de salida, las estrategias y las metas que nos orienten.

Entre las recientes «teorías de la integración europea» está el constructivismo. El presente artículo pretende ser una introducción a él, en su aplicación a la UE, presentando las conceptualizaciones fundamentales, metodologías, debates y tendencias recientes. Antecede una primera parte que se refiere al constructivismo en las Relaciones Internacionales, expuesto sintéticamente en torno a tres dimensiones: ontológica, epistemológica y metodológica. A continuación el artículo se centra en la Unión Europea y se lleva a cabo siguiendo un hilo cronológico en la aplicación del constructivismo mediante la presentación de algunos autores relevantes y vigorosos debates. No se pretende hacer una síntesis del constructivismo, ni siquiera de su aplicación a la UE, sino una introducción, trasmitiéndolo y facilitando su acceso con un cierto orden y con la esperanza ya mencionada de que el acervo teórico comunitario y su desarrollo ulterior contribuyan a reorientar a la Unión en la situación actual. 


\section{Los constructivismos en las Relaciones Internacionales}

Aun prescindiendo de las diversas raíces remotas del constructivismo, resulta ineludible la referencia más cercana a la obra de Berger y Luckmann, La Construcción Social de la Realidad de 1966, cuyas tesis fundamentales son «que la realidad se construye socialmente y que la sociología del conocimiento debe analizar los procesos por los cuales esto se produce. Los términos clave de dichas tesis son "realidad" y "conocimiento"» $;^{1}$ «es justamente el carácter dual de la sociedad en términos de factibilidad objetiva y significado subjetivo lo que constituye su "realidad sui generis"».2

Sin embargo, quedaba todavía un largo camino hasta que la Sociología jugase un papel relevante en las Relaciones Internacionales pues «el supuesto sobre la "construcción social de la realidad" (Berger y Luckmann 1966) no se refiere aún a ninguna decisión sobre qué construcciones sociales de qué actores en las relaciones internacionales son eficaces y por eso importantes para el investigador». ${ }^{3}$

Una serie de cambios históricos en la sociedad internacional de los últimos lustros del siglo xx: desaparición del comunismo y de la URSS, final de la «guerra fría», transición hacia la Unión Europea, van a hacer sentir las insuficiencias de las teorías predominantes en las Relaciones Internacionales y propiciar el «giro constructivista». Zehfuss lo presenta a través de tres académicos claves: Nicholas Onuf, quién en 1989 introdujo el término, se centra en la relación hechos, palabras, mundo; Friedrich Kratochwil, para el que el contexto de normas y reglas proporciona la base para la intersubjetividad y de este modo la posibilidad de comprender la política como acción de sentido y cuestiones normativas; y Alexander Wendt, que contribuyó decisivamente a su difusión privilegiando las identidades de los actores construidas en las interacciones. ${ }^{4}$ Algunos autores incluirían también a Emanuel Adler.

A continuación nos referimos breve y sintéticamente a los constructivismos en las Relaciones Internacionales en torno a tres dimensiones: ontológica, epistemológica y metodológica.

${ }^{1}$ BERGER, P.L. y LUCKMANN, T., La Construcción Social de la Realidad, Amorrortu Editores, Buenos Aires, 1998 (15 ed.), p. 13.

2 Ibid., p. 35.

${ }^{3}$ HARNISCH, S., «Sozialer Konstruktivismus», Handbuch der Internationalen Politik, Springer, 2010, 1, p. 103.

4 ZEHFUSS, M., Constructivism in International Relations. The Politics of Reality, Cambridge University Press, Cambridge, 2002. 


\section{Ontología}

\section{a) LAS IDEAS FRENTE AL MATERIALISMO}

Para el constructivismo el mundo social, y específicamente el sistema internacional, es una construcción humana basada en ideas compartidas. ${ }^{5}$ Los hechos sociales existen porque atribuimos intersubjetivamente significados a determinados objetos, acciones y acontecimientos. Una vez que los representamos colectivamente se convierten en realidad social con consecuencias reales. Esto no presupone necesariamente la negación de la existencia de realidades materiales, pero se destaca el factor humano, subjetivo, de ideación, en la vida social. Lo material en sí carece de significado y necesita ser comprendido mediante conceptos sociales que definen su significado. Las ideas se manifiestan en formas diferentes: identidades, intereses, roles sociales, normas, culturas políticas, productos todos de un proceso de construcción social. «El núcleo irreductible del constructivismo para las relaciones internacionales es el reconocimiento que la realidad internacional está construida socialmente». ${ }^{6}$

\section{b) LA CONSTITUCIÓN MUTUA DE ACTORES Y ESTRUCTURAS}

Los actores y sus ideas son generados dentro de estructuras sociales; las estructuras sociales son generadas a su vez por los actores y sus ideas. Actores y estructuras se construyen mutuamente, sin que haya primacía de unos o de otras. «Para el constructivismo, del mismo modo que las estructuras sociales son ontológicamente dependientes de y, por tanto, constituidas por las prácticas y formas de entender de los agentes, los poderes causales e intereses de estos agentes, a su vez, están generados y, por tanto, explicados por las estructuras. En definitiva, agentes y estructuras, aunque ontológicamente distintos, son entidades mutuamente constituidas». ${ }^{7}$ Frente al individualismo racionalista, el constructivismo plantea un enfoque estructuralista u holístico, en el que los actores están socialmente contextualizados, al mismo tiempo que actúan sobre esos contextos.

\section{c) EL CAMBIO}

La relevancia de las ideas y la constitución mutua de actores y estructuras abren ventanas de posibilidad al cambio en las relaciones internaciona-

5 SODUPE, K., La Teoría de las Relaciones Internacionales a Comienzos del siglo XXI, Universidad del País Vasco/Euskal Herriko Unibertsitatea, Bilbao, 2003, pp. 161 y 166.

${ }^{6}$ HURD, I., «Constructivism», en REUS-SMIT, C. y SNIDAL, D. (eds.), The Oxford Handbook of International Relations, Oxford University Press, Oxford, 2008, p. 305.

7 SODUPE, K., op. cit., p. 176. 
les, no obstante la probable resistencia de los poderes e instituciones dominantes. Las ideas, los valores, las identidades, los intereses, los actores y las estructuras se generan, al menos en parte, endógenamente en los procesos intersubjetivos creadores de significado en las relaciones internacionales, lo que puede abrir un espacio al cambio. Incluso la dimensión ética - la ética cuenta en la política mundial ${ }^{8}$ - puede encontrar una oportunidad según algunos constructivistas, que han explorado empíricamente esa orientación.

\section{Epistemología}

Según los constructivistas también el conocimiento de la realidad es construido socialmente. Muchos de ellos, no obstante, no renuncian a teorías explicativas de base empírica que pueden ayudarnos a discernir qué conceptualización es mejor, dado que no todas son iguales. El criterio, sin embargo, no es la adecuación a una realidad objetiva, sino la correspondencia con las situaciones del mundo.

El realismo científico de Wendt y de otros trata de hacer compatibles la epistemología «positivista» con la ontología idealista y estructuralista, mientras otros más radicales lo rechazan. La división entre positivistas y post-positivistas dentro del constructivismo es profunda y por ahora duradera. Para los primeros, el sistema internacional socialmente construido tiene pautas que posibilitan las generalizaciones y el falseamiento de hipótesis. Para los post-positivistas los datos de la vida social no son del todo objetivables, ni los observadores completamente autónomos del objeto de estudio, ni las relaciones sociales adecuadamente separables en causas y efectos; la investigación social tiene que ver con la construcción social de sentido, lo que reafirma la indispensabilidad de la interpretación. ${ }^{9}$

Otro gran debate epistemológico entre racionalistas y constructivistas, y también en parte entre estos últimos, es el de las teorizaciones causales y/o teorizaciones constitutivas. Los racionalistas buscan relaciones del tipo «X causa $Y »$ que suponen que ambas son diferentes, $X$ precede a $Y$, y ésta no existiría de no ser por aquélla, y desarrollan sus explicaciones en términos de variables independientes y dependientes. Para los constructivistas esa teorización causal ha de ser completada o substituida por una teorización constitutiva. La pregunta de ésta: «¿cómo es posible que ocurra...?» orienta la respuesta hacia las condiciones estructurales socialmente construidas. La diferencia decisiva con la teorización causal está en la inseparabilidad ló-

8 PRICE, R., «The Ethics of Constructivism», en REUS-SMIT y SNIDAL (eds.), op. cit., p. 317.

${ }^{9}$ HURD, I., op. cit., p. 307. 
gica y temporal de $\mathrm{X}$ e Y, no existiendo causación, sino constitución. ${ }^{10} \mathrm{La}$ posibilidad o no de afirmaciones verdaderas independientes del observador y la posibilidad o no en principio de afirmaciones causales, además de las constitutivas, divide a los constructivistas moderados de los radicales.

\section{Metodología}

Tras unas referencias a la ontología - «¿cómo conceptualizan los investigadores lo que estudian?»- y a la epistemología — «¿cómo conocen los investigadores lo que conocen?»-Klotz y Lynch entran en la metodología del constructivismo: «¿cómo los investigadores seleccionan sus herramientas (tools)?». La definición de los conceptos nucleares es el punto de partida y debe tener primacía y orientar la elección de los instrumentos. ${ }^{11}$ Esto apunta a la preferencia constructivista por el método holístico frente al individualismo racionalista, por las relaciones constitutivas antes que las causales y por la interpretación más allá de las explicaciones científicas del positivismo. Klotz y Lynch organizan a continuación la selección de diferentes metodologías y técnicas en torno a cuatro conceptos claves constructivistas: las estructuras, los agentes, las identidades y los intereses.

Las estructuras están formadas por significados estables, mientras los conflictivos abren la posibilidad a la innovación y a la reforma. Hay que explorar los contextos dentro de los que los significados forman las estructuras y generan formas alternativas, cuyas manifestaciones son analizables a nivel de macro-historia, genealogía y observación participante. «Una ontología constructivista de constitución mutua cuestiona el estructuralismo (de diferentes tipos) devolviendo un rol a los agentes en la reproducción de los órdenes sociales». ${ }^{12}$

Respecto a los agentes, los constructivistas parten del presupuesto que los seres humanos tienen intenciones e interpretaciones que afectan a las estructuras, por lo que «las metodologías que destacan el razonamiento y la comunicación captan mejor estos procesos de construcción, deconstrucción y reconstrucción», ${ }^{13}$ y señalan tres: la narrativa, el marco (framing) y la etnografía.

Las identidades - qué somos - son vistas por los constructivistas como relaciones sociales y abogan por «metodologías orientadas procesalmente»: la

${ }^{10}$ HARNISCH, S., op. cit., p. 106.

${ }^{11}$ KLOTZ, A. y LYNCH, C., Strategies for Research in Constructivist International Relations, M.E. Sharpe, Armonk, Nueva York, 2007, p. 16.

12 Ibid., p. 41.

13 Ibid., p. 45. 
estructura constituyendo a los agentes; los agentes constituyendo la estructura. Se sugiere yuxtaponer las estrategias de investigación de la psicología social, que destacan la autoconstrucción de la identidad dentro de un contexto social, y de la representación, que enfatiza la imposición discursiva de la identidad en un contexto histórico, como explicaciones comparables o complementarias acerca del cambio de identidades. ${ }^{14}$

Finalmente, los intereses - qué queremos - son sustentados por las identidades y no por fuentes materiales, como es el presupuesto común en las Relaciones Internacionales. Su formación es un proceso: ¿por qué?, ¿cómo?, ¿en qué condiciones? «Conceptualizar los intereses como el producto de interacciones y de identidades institucionalizadas presupone un contenido intersubjetivo». ${ }^{15}$ La investigación tiende a seguir dos direcciones: la acción comunicativa y los juegos de lenguaje.

Como conclusión del camino, Klotz y Lynch «animan al uso creativo de todos los métodos, en tanto en cuanto los investigadores no reclamen la objetividad o la verdad universal». ${ }^{16}$

En los últimos veinte años el constructivismo ha ido creciendo entre debates, por un lado con el realismo y el racionalismo, tanto en la dimensión ontológica (idealismo frente a materialismo; estructuralismo u holismo frente a individualismo) como epistemológica (compatibilidad con y grado de positivismo; teorización constitutiva y/o causal) y por otro entre los constructivistas moderados y radicales respecto a la realidad social, la constitutividad mutua estructura-agentes, el positivismo-post-positivismo y las teorizaciones. ${ }^{17}$ Las diferentes posiciones entre los constructivistas en estos debates y las correspondientes diversidades metodológicas hacen imposible referirse a un único constructivismo; éste tampoco sería equiparable a las grandes «teorías substantivas» de las Relaciones Internacionales, ${ }^{18}$ aunque hay que reconocer sus crecientes aportes a la comprensión de la política internacional y la proliferación de estudios empíricos.

\section{El constructivismo social y su aplicación inicial a la Unión Europea}

En el último decenio del siglo XX se sentía la insuficiencia de las teorías clásicas de la integración europea - más específicamente del neofuncionalismo y del intergubernamentalismo - para dar razón de los recientes

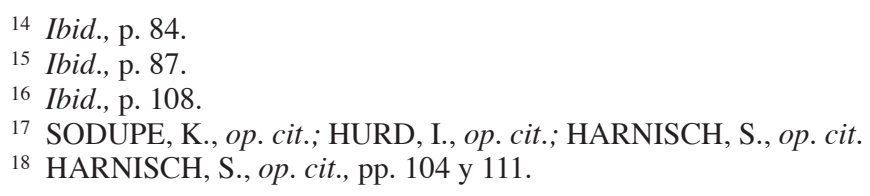


fenómenos y tendencias de ésta y se apuntaba a nuevos caminos. Abogaban algunos por tomar más seriamente el giro constructivista de las Relaciones Internacionales y aplicar el constructivismo social al estudio de la Unión Europea otorgando un mayor papel a las ideas. ${ }^{19}$ Parecía, por otra parte, que algunas de las especificidades de la UE eran especialmente adecuadas y prometedoras para la aplicación y eventual desarrollo del constructivismo social. $^{20}$

\section{The Social Construction of Europe}

En diciembre de 1999 se publicó un número especial del Journal of European Public Policy, que apareció dos años después en forma de libro bajo el título de The Social Construction of Europe y se considera la obra mayor que abrió el estudio de la Unión Europea a una aproximación constructivista.

Christiansen, Jorgensen y Wiener nos dicen en la Introducción que el libro trata de aplicar la reciente perspectiva del constructivismo en el estudio de las Relaciones Internacionales a la integración europea, destacando «el impacto de "las ontologías sociales" y "las instituciones sociales" en el continuo proceso de integración europea» y buscando los instrumentos para analizar el impacto de la intersubjetividad y el contexto social. ${ }^{21}$ «La propia integración europea ha cambiado a lo largo del tiempo y es razonable asumir que en el proceso han cambiado igualmente la identidad de los actores y subsiguientemente sus intereses y comportamiento». ${ }^{22}$ Esta ontología social (conciencia humana y factores ideales) tiene particulares ramificaciones epistemológicas. ¿Dónde está el giro constructivista en el estudio de la integración? Según los autores, el proyecto constructivista de examinar críticamente los procesos transformativos de la integración europea tendrá un impacto en el desarrollo de teorías de alcance medio, la construcción de marcos de análisis y la meta-teorización. A continuación delinean los elementos de tal marco, que hasta ahora ha faltado: 1) Reglas y normas de la gobernanza europea; 2) Comunidad política y formación de la identi-

${ }^{19}$ RISSE-KAPPEN, T., «Exploring the Nature of the Beast: International Relations Theory and Comparative Policy Analysis Meet the European Union», Journal of Common Market Studies 34, 1, 1996, pp. 53-80.

${ }^{20}$ EILSTRUP-SANGIOVANNI, M., Debates on European integration. A Reader, Palgrave-Macmillan, Houndmills, 2006, pp. 397-402.

${ }^{21}$ CHRISTIANSEN, T., JORGENSEN, K.E. y WIENER, A. (eds.), The Social Construction of Europe, SAGE Publications, Londres, 2001, p. 1.

22 Ibid., p. 2. 
dad; y 3) Discursos, acción comunicativa y rol de las ideas. Reconocen con modestia, no obstante, que «muchos presupuestos derivados del constructivismo están ya presentes en unas cuantas contribuciones importantes para la investigación de la integración europea». ${ }^{23}$

La Parte I se refiere a la teorización de la integración europea y el constructivismo social. En su propio artículo Checkel muestra «cómo un corte constructivista social del proceso de construcción de instituciones explica aspectos claves de la europeización». ${ }^{24}$ Hasta ahora la mayoría de los trabajos sobre integración europea habían considerado las instituciones, en el mejor de los casos, como variables intervinientes, perdiendo la perspectiva sociológica de cómo las instituciones europeas, mediante procesos de interacción, pueden construir las identidades e intereses de los Estados miembros y de grupos dentro de éstos. «Los constructivistas sociales modernistas nos recuerdan que el estudio de la política - o integración - no es precisamente acerca de agentes con preferencias fijas que interactúan en intercambio estratégico. Buscan más bien explicar teóricamente ambos: el contenido de las identidades/preferencias del actor y los modos de interacción social». ${ }^{25}$ Considera Checkel a continuación dos áreas en las que el constructivismo puede contribuir al estudio de la integración: 1) los procesos de aprendizaje y socialización en el nivel europeo, sosteniendo que, frente a las identidades fijas, «los intereses e identidades del agente son configurados a través de la interacción»; ${ }^{26}$ y 2) el aspecto normativo de la europeización en el nivel nacional; las normas sociales (menos formalizadas) son vistas como compartidas comprensiones colectivas con exigencias de comportamiento para los actores: ¿mediante qué procesos se constituyen?, ¿cómo, alcanzado el nivel nacional, interactúan y socializan a los agentes? Finaliza Checkel recordando que «los rompecabezas más interesantes están en el nexo donde intersectan estructura y agentes». ${ }^{27}$

La parte II nos presenta diversas perspectivas constructivistas en los estudios de integración europea. Se trata de estudios de aplicación del constructivismo social a temas más delimitados y específicos, llevando a cabo cierto grado de análisis empírico. Así se va dibujando «en la práctica» el constructivismo social, aunque los autores se remontan de vez en cuando a cierto nivel teórico. Díez explora el rol del lenguaje en la construcción de la UE: «he argüido que el lenguaje hace más que describir; que todos nuestros

23 Ibid., p. 18.

24 CHECKEL, J.T., «Social Construction and European Integration» en CHRISTIANSEN, T., JORGENSEN K.E. y WIENER A. (eds.), op. cit., p. 50.

25 Ibid., p. 53.

26 Ibid.

27 Ibid., p. 62. 
relatos del mundo (y por tanto de la gobernanza europea) están incorporados en ciertos discursos; que el significado de las palabras depende de su contexto discursivo; que este contexto no es rígido, sino que está en constante, aunque lento, flujo; y que la reciente transformación del contexto discursivo posibilita la construcción de Europa como una "red"».28 Fierke y Wiener, por su parte, nos recuerdan que «los constructivistas han cuestionado el presupuesto racionalista de intereses exógenamente dados, arguyendo que los intereses son construidos en circunstancias históricas específicas, esto es, un contexto de normas sociales y culturales configura la identidad y el comportamiento del actor». ${ }^{29}$ En su trabajo «Discursos de Globalización e Identidades Europeas» nos ofrece Rosamond una apretada formulación sintética del constructivismo centrada en los juegos entorno/intereses, agentes/estructura (entorno) e identidades/entorno y de la globalización. ${ }^{30}$

La Parte III está dedicada a un debate de fondo. Desde el racionalismo y el intergubernamentalismo liberal Moravcsik expresa su decepción con el constructivismo debida a la falta de voluntad de éste de someter sus proposiciones a cualquier riesgo de falseamiento empírico, lo que a su juicio se debe a la ausencia de dos elementos críticos de las ciencias sociales: 1) hipótesis distintas contrastables; y 2) métodos para contrastarlas contra teo-

${ }^{28}$ DÍEZ, T., «Speaking "Europe": The Politics of Integration Discourse» en CHRISTIANSEN, T., JORGENSEN, K.E. y WIENER, A. (eds.), op. cit., p. 96.

${ }^{29}$ FIERKE, K.M. y WIENER, A., «Constructing Institutional Interests: EU and NATO Enlargement», en CHRISTIANSEN, T., JORGENSEN, K.E. y WIENER, A. (eds.), op. cit., p. 123.

${ }^{30}$ ROSAMOND, B., «Discourses of Globalization and European Identities» en CHRISTIANSEN, T., JORGENSEN, K.E. y WIENER, A. (eds.), op. cit., p. 164. «La proposición constructivista básica, como lo hace notar Checkel, es que se le da significado al entorno en el que operan los actores por medio de los procesos de construcción social en curso. Esto quiere decir que hay conexión inherente entre la construcción social del entorno "externo" y los intereses que adquieren los actores (Checkel 1998: 325-6). Los intereses se conciben mejor como endógenos, y no exógenos, a la interacción. Los constructivistas tratan de diluir la oposición entre agentes y estructura. Los intereses de los agentes no son estructurados por su entorno. Ellos ayudan a hacer su entorno y su entorno ayuda a hacerles a ellos. El entorno dentro del que los actores operan es una estructura intersubjetiva que también contribuye a la creación de normas que gobiernan el comportamiento y los límites de lo posible (Wendt 1992, 1994). Esto quiere decir que no solo los intereses, sino también las identidades están ligadas a estos procesos sociológicos. "Nosotros" somos lo que hacemos de nosotros mismos y lo que "nosotros" hacemos de nosotros mismo estará referido a lo que "nosotros" hacemos de nuestro entorno. Los tratamientos constructivistas de renglones de la política internacional tales como la "anarquía" (Wendt 1992) y el "interés nacional" (Weldes 1996) han tendido a seguir este camino. La "globalización" podría pensarse como una especie similar de estructura intersubjetiva que proporciona una poderosa racionalidad ordenadora y por tanto ayuda a crear un mundo definido por esa racionalidad ordenadora como comportamiento e identidades del actor ajustadas de acuerdo (McNamara 1997)». 
rías alternativas o hipótesis nulas. ${ }^{31}$ Por su parte, Steve Smith, desde el reflectivismo, va a negar al constructivismo, por un lado, el «punto medio» («middle ground») $)^{32} \mathrm{y}$, por otro, la unidad: hay muchos constructivismos sociales. En el último capítulo del libro les responden Thomas Risse y Antje Wiener. Frente a Smith defienden el middle ground del constructivismo social en el sentido que comparte con el racionalismo la epistemología (búsqueda de la verdad y creencia en la posibilidad de generalización causal en forma de teorías de alcance medio), pero no la ontología; mientras que respecto al reflectivismo comparte la ontología (comprensiones sociales y sistemas de significados), pero no la epistemología. Respecto a las críticas de Moravcsik hacen varias puntualizaciones: 1) el presente libro no trataba de «contrastar hipótesis»; 2) Moravcsik entiende mal el constructivismo social, que no pretende presentar una alternativa a las teorías substantivas de Relaciones Internacionales o de integración europea, sino que es una aproximación meta-teórica, que ofrece una ontología; y 3) sorprende el cargo de Moravcsik de que en este libro no hay una sola proposición formulada de modo que pueda ser declarada empíricamente inválida; las hay en Checkel, Rosamond, Marcusse et al.

En Conclusión, Christiansen, Jorgensen y Wiener editaron en The Social Construction of Europe una obra seminal para el intento de aplicar el constructivismo social a la integración europea. Reconocieron al mismo tiempo el desarrollo aún incipiente de éste y lo mucho que quedaba todavía por hacer intelectualmente en el esfuerzo por aplicarlo a los estudios de integración europea, a los que creían poder contribuir con aportes relevantes desde la nueva aproximación.

\section{El debate racionalismo-constructivismo}

El debate entre constructivistas sociales y racionalistas continuó: «¿Qué forma tendrían las hipótesis constructivistas empíricamente contrastables sobre integración europea y cuáles son los retos metodológicos implicados en su contrastación?» se pregunta Checkel ante las críticas de Moravcsik. ${ }^{33}$ Sugiere entonces analizar el rol de la socialización y, tras distinguir en ella la persuasión manipulativa de la argumentativa, formula cinco proposicio-

31 MORAVCSIK, A., «Constructivism and European Integration: A Critique», en CHRISTIANSEN, T., JORGENSEN, K.E. y WIENER, A. (eds.), op. cit., p. 185.

32 SMITH, S., «Social Constructivisms and European Studies», en CHRISTIANSEN, T., JORGENSEN, K.E. y WIENER, A. (eds.), op. cit., p. 191.

33 CHECKEL, J.T. y MORAVCSIK, A., "A Constructivist Research Program in EU Studies», European Union Politics, 2, 2, 2001, p. 219. 
nes o hipótesis respecto a esta última. ${ }^{34}$ «El reto es medir la persuasión/socialización y el (posible) cambio de preferencias», 35 para lo que propone usar como método básico el trazado del proceso (process-tracing) y tres técnicas: entrevistas, análisis cualitativo de contenido y consulta de registros documentales. Reconoce Checkel que, aunque se lleva más de treinta años trabajando los efectos socializadores del proyecto europeo, queda mucho por hacer metodológicamente e incluso conceptualmente y con su aproximación espera contribuir a rectificar algunos problemas concernientes a las condiciones iniciales y a los procesos específicos promotores de la socialización: cuando, en qué condiciones, mediante qué mecanismos ocurre.

¿Las hipótesis y la metodología propuestas ahora por Checkel resuelven los problemas de la investigación constructivista que Moravcsik criticó? ${ }^{36}$ Éste precisa que «lo que distingue los análisis racionalistas de los constructivistas no es el mero hecho de que los actores estatales y societales tengan ideas consistentes con sus acciones, sino la independencia causal de esas ideas - su fuente, variación y la naturaleza de su vínculo con la política-». ${ }^{37}$ Aunque hay no poco laudable en las cinco hipótesis concretas de Checkel, a juicio de Moravcsik no son distintivas del constructivismo, faltando una teoría constructivista suficientemente fuerte y distinta, que la metodología de trazado del proceso (process tracing) no es capaz de suplir. Tampoco la dicotomía entre persuasión manipulativa y argumentativa es conceptualmente satisfactoria. «Desgraciadamente, al final $-\mathrm{y}$ en gran parte precisamente porque se impone a sí mismo exigencias teóricas y metodológicas más altas que las que aceptan sus compañeros constructivistas - Checkel es incapaz de mantener sus promesas», concluye Moravcsik. ${ }^{38}$

Tratando de hacer un balance del debate y de establecer puentes entre constructivistas y racionalistas, Checkel escribe una réplica: «En un punto

34 Ibid., p. 222. Las cinco proposiciones o hipótesis sobre la persuasión argumentativa (pa) son: 1) la pa es más efectiva probablemente cuando el persuadido está en un nuevo e incierto entorno; 2) la pa es más efectiva probablemente cuando el persuadido tiene pocas creencias previas inconsistentes con el mensaje del persuasor; 3) la pa es más efectiva probablemente cuando el persuasor es un miembro autoritativo del grupo al que pertenece el persuadido; 4) la pa es más efectiva probablemente cuando el persuasor no da lecciones o exige, sino que actúa desde principios deliberativos; y 5) la pa es más efectiva probablemente cuando la interacción persuasor-persuadido ocurre en contextos menos politizados y más aislados.

35 Ibid., p. 50.

${ }^{36}$ Ibid., p. 226: «I criticized constructivist research on European integration for its paucity of distinctive testable hypothesis and objective methods for testing those it has against the best alternative theories or a null hypothesis (random state behavior)».

37 Ibid., pp. 227 y 230.

38 Ibid., p. 239. 
fundamental estamos de acuerdo Moravcsik y yo, en que se necesita una atención sostenida al desarrollo de la teoría substantiva para que los análisis constructivistas de la integración puedan avanzar; el reto es bajarlos de las "nubes" meta-teóricas y socio-teóricas. No estamos de acuerdo acerca del alcance de mis esfuerzos en esa dirección; Moravcsik presenta el intento como un estrellarse al aterrizar; yo lo veo como un descenso controlado, necesitado de ciertas correcciones del curso, pero encaminado a una llegada segura». ${ }^{39}$ Especifica a continuación tres puntos de acuerdo. 1) las proposiciones de alcance medio son el camino de avance; 2) necesidad de altos estándares metodológicos y de metodologías de investigación transparentes; y) mis hipótesis se solapan parcialmente con las de los racionalistas, y dos de desacuerdo: 1) conceptualización de la persuasión; y 2) sobre la posibilidad y necesidad de medir las preferencias de los agentes sociales. En definitiva, ¿qué clase de teorías de alcance medio necesitamos? Moravcsik comenzaría especificando hipótesis claras y preferentemente derivadas deductivamente. El estilo de análisis es el del «gladiador». "Yo favorecería hipótesis de alcance medio construidas mediante un juego creativo entre deducción e inducción». ${ }^{40}$ Las críticas de Moravcsik nos ayudan a salir de las «nubes», aunque discrepemos acerca de cómo llegar al destino final, concluye Checkel.

\section{Tendiendo puentes entre constructivismos sociales}

Los grandes debates del constructivismo con otras aproximaciones, así como dentro del mismo, fueron perdiendo fuerza en un ambiente intelectualmente más pluralista y con una actitud de tender puentes. ${ }^{41} \mathrm{Al}$ mismo tiempo se iba consolidando como uno de los enfoques imprescindibles tanto en las Relaciones Internacionales como en los estudios de integración europea. En éstos se fue desarrollando sobre todo, como ya se ha mencionado, una de las variantes más moderadas, el constructivismo social, según Risse:

«basado sobre una ontología social que insiste en que los agentes humanos no existen independientemente de su entorno social y sus sistemas de significados compartidos colectivamente (cultura en sentido amplio)... El punto crucial es que los constructivistas insisten en la mutua constitutividad de estructuras y agentes sociales (Adler 1997: 324-5; Wendt 1999:

39 Ibid., p. 240.

40 Ibid., p. 243.

41 JACHTENFUCHS, M., «Deepening and widening integration theory», Journal of European Public Policy 9:4, 2002, pp. 651 y 654. 
cap. 4). El entorno social en el que nos encontramos define (constituye) quienes somos, nuestras identidades como seres sociales. "Nosotros" somos seres sociales, incorporados en varias comunidades sociales relevantes. Al mismo tiempo, los agentes humanos creamos, reproducimos y cambiamos la cultura mediante nuestras prácticas diarias». ${ }^{42}$

No se trata, como ya se indicó, de otra teoría substantiva de la integración, sino de una aproximación ontológica y epistemológica - a la integración europea en nuestro caso - ni pretende substituir a otras aproximaciones, sino complementarlas, destacando que los intereses de los actores se van haciendo en el proceso, no son exógenos. La pertenencia a la UE cuenta (matters): «los constructivistas enfatizan que la UE afecta profundamente a las prácticas discursivas y de comportamiento, que ha devenido parte del "mobiliario social" con el que los actores sociales y políticos tienen que tratar diariamente». ${ }^{43}$ Se pasa de la lógica del «conseguidismo» (consequentialism) a la lógica de lo apropiado (appropriateness).

También Checkel ve el constructivismo como «una orientación analítica particular», aplicada a Europa en el presente caso, aunque posibilita al mismo tiempo iluminar cuestiones más generales. Distingue tres variantes de constructivismos sociales. El constructivismo convencional «examina el rol de las normas, y en menos casos la identidad, que configuran los resultados políticos internacionales»; ${ }^{44}$ tiene una orientación epistemológica positivista y su punto de partida metodológico es el estudio de casos cualitativos de trazado del proceso; aboga por la construcción de puentes. El constructivismo interpretativo «explora el rol del lenguaje que media y construye la realidad social», ${ }^{45}$ propugna epistemologías post-positivistas. El constructivismo crítico/radical «mantiene el foco lingüístico, pero añade una dimensión explícitamente normativa». ${ }^{46}$ Otra rama del constructivismo post-positivista sería el habermasiano, que estudia Europa en términos de deliberación y legitimidad.

Los constructivistas convencionales que estudian Europa están orientados empíricamente y con frecuencia al trazado del proceso (process

${ }^{42}$ RISSE, T., «Social Constructivism and European Integration» en WIENER, A. y DÍEZ, T. (eds.), European Integration Theory, Oxford University Press, Oxford, 2009 (2. ${ }^{\mathrm{a}}$ ed.), pp. 145-146. Puede verse SCHWOK, R., Théories de l'intégration européenne, Montchrestien, Paris, 2005, pp. 112ss.

43 Ibid., p. 148.

${ }^{44}$ CHECKEL, J.T., «Constructivism and EU Politics», en JORGENSEN, K.E.; POLLACK, M. y ROSAMOND, B. (eds.), Hadbook of European Union Politics, Sage Publications, London, 2006, p. 58.

45 Ibid.

46 Ibid. 
tracing $),{ }^{47}$ pero la orientación empírica se paga con falta de claridad epistemológica; el trazado del proceso entra en contradicción con epistemologías interpretativas que están en el núcleo de la teoría constructivista. Existe un auténtico problema con el positivismo: «los constructivistas convencionales necesitan explicar más cuidadosamente sus supuestos metodológicos», ${ }^{48}$ para lo que podrían ayudarles los constructivistas interpretativos y los crítico/radicales. Es necesario complementar las metodologías positivistas con otras basadas en técnicas interpretativas, por ejemplo, tomando en serio el lenguaje o la argumentación, como algunos ya lo han hecho.

Dos grandes carencias son denunciadas por Checkel. La primera respecto al poder, que ha desaparecido, especialmente en los constructivistas convencionales y los habermasianos estudiosos de la deliberación. Hay que buscarlo de nuevo y reintroducirlo, tanto epistemológicamente, para lo que podrían ayudar las intuiciones del constructivismo interpretativo y crítico/ racional, como académicamente, para lo que debería mirarse a la teoría de las Relaciones Internacionales. La segunda carencia se refiere al olvido de lo doméstico y nacional, que los constructivistas de la UE deberían integrar dinámicamente, yendo arriba y abajo a través de los diferentes niveles, enfatizando la simultaneidad de lo internacional y lo doméstico.

Finalmente se señala que una «comunidad constructivista» es una especie de oxímoron, pues no existen ni es fácil que existan entre los constructivistas que estudian Europa estándares comunes, especialmente respecto a la epistemología y la metodología. Hacia el futuro se abren dos caminos: a) dejar que continúen las tendencias presentes; o b) construir puentes dentro de la comunidad de académicos constructivistas. Checkel aboga por un pluralismo conceptual y meta-teórico en el estudio constructivista de Europa - no por la unidad.$-{ }^{49}$

Los constructivistas estudiosos de la Unión Europea han desarrollado sobre todo tres problemáticas conceptuales: la socialización y el aprendizaje, la construcción social de una identidad europea y el constructivismo estratégico como reacción a la falta de consideración del poder, problemáticas constructivistas que continúan sometidas a importantes desafíos cuando

47 Ibid., p. 59. «El método de trazado del proceso (process tracing method) intenta identificar el proceso causal interviniente - la cadena causal y el mecanismo causal - entre una variable (o variables) independiente y el resultado de la variable dependiente. ... El trazado del proceso fuerza al investigador a tener en cuenta la equifinalidad, esto es, a considerar vías alternativas a través de las cuales el resultado podría haber ocurrido y ofrece la posibilidad de dibujar un mapa de la o de las potenciales vías causales consistentes con el resultado y la evidencia del trazado del proceso en un único caso (Bennet y George, 2005: 206-7)».

48 Ibid., p. 61.

49 Ibid., p. 70. 
intentan afrontar ciertas críticas formuladas desde las Relaciones Internacionales. ${ }^{50}$

\section{Estudios empíricos sobre identidad(es) europea(s)}

Los constructivistas sociales fueron bajando de las nubes meta-teóricas y aumentaron notablemente los estudios empíricos, entrando así en la «ciencia social normal». ${ }^{51} \mathrm{Al}$ final del primer decenio del siglo XXI, Harnisch estimaba que el gran número de estudios empíricos desde el constructivismo había realizado una contribución propia a la mejor comprensión de la política internacional: 1) haciendo patente la constitución mutua de actores y estructuras; 2) tematizando el significado constitutivo de las construcciones sociales para las identidades/roles de los actores, su definición de intereses y sus actuaciones; y 3 ) mostrando la posibilidad de modelar la trasformación de normas, identidades, etc. a través de la acción comunicativa. ${ }^{52}$ Señalaba también los ámbitos privilegiados por estos estudios empíricos constructivistas: política de seguridad, derechos humanos, transformación del efecto constitutivo de la norma de soberanía para las relaciones internacionales, aprendizaje en política internacional, construcción de comunidades epistémicas y socialización de los actores internacionales en las comunidades e instituciones existentes, principalmente en la Unión Europea.

El tema de la identidad europea muy pronto llegó a ser objeto de estudio de las aproximaciones constructivistas sociales, pues parecía responder bien a la ontología y epistemología de éstas así como a sus recientes necesidades y tendencias empíricas. ${ }^{53}$

Checkel y Katzenstein abogan por una perspectiva multidisciplinar. Entienden las identidades sociales y políticas como «representaciones compartidas de un yo mismo (self) colectivo en cuanto se reflejan en el debate público, los símbolos políticos, las memorias colectivas y la competición de las elites por el poder. Consisten también en creencias colectivas acerca de

50 SAURUGGER, S., Théories et concepts de l'intégration européenne, Presses de la Fondation Nationale des Sciences Politiques, Paris, 2009, pp. 176 y 190.

${ }^{51}$ RISSE, T., op. cit. p. 158.

52 HARNISCH, S., op. cit., p. 110.

53 Ya en 2004 Risse reiteraba tres puntos - posteriormente añadiría el cuarto - respecto a la investigación en curso sobre la identidad europea: $1 .^{\circ}$ ) la identidad europea asume una posición central en el relato constructivista; $2^{\circ}{ }^{\circ}$ ) se destacan los efectos constitutivos de la europeización sobre las identidades sociales; $3^{\circ} .^{\circ}$ importancia de analizar la construcción discursiva de los significados; y $4^{\circ} .^{\circ}$ baja probabilidad de que las identidades sociales permanezcan fijas por largo tiempo (RISSE, T., op. cit., pp. 155-156). 
la definición del grupo y de la pertenencia a él, que son compartidas por la mayoría de los miembros. Entendemos que las identidades son reveladas por las prácticas sociales así como por las actitudes políticas, configuradas por las estructuras sociales y geográficas y los contextos nacionales». ${ }^{54} \mathrm{Su}$ evolución es el resultado de un proceso social abierto y de proyectos políticos específicos y existen en plural. Checkel y Katzenstein adoptan una aproximación constructivista crítica para el estudio de las identidades, resaltando la importancia de la política y de la politización, «un proceso que hace que las cuestiones formen parte del juego político (politics)». ${ }^{55}$ Cuando se reacciona a retos o amenazas planteados por otros, la identidad de la Unión Europea suele ser percibida como «una comunidad de valores compartidos», mientras que cuando el reto consiste en crear algo propio, Europa se suele revelar como «una comunidad de extraños». ${ }^{56}$ Hoy las identidades europeas están abiertas y son plásticas a múltiples interpretaciones, emergiendo de la mezcla y confluencia de variedad de procesos y proyectos. Su estudio requiere otra clase de aproximaciones académicas y de rigor analítico «más concernido con explicar la dinámica de la identidad que de ajustarla a marcos teóricos preconcebidos». ${ }^{57}$

También Risse ha estudiado desde una perspectiva constructivista social la emergencia de una identidad y de una esfera pública europeizadas. Desde una epistemología constructivista aplica una metodología positivista mode-

${ }^{54}$ CHECKEL, J.T. y KATZENSTEIN, P.J. (eds.), European Identity, Cambridge University Press, Cambridge, 2009, p. 4.

55 Ibid., p. 11.

56 Ibid., p. 214. Dario Castiglione titula su trabajo en este mismo libro «Political identity in a community of strangers» argumentando que «la construcción de la identidad política europea no necesariamente descansa en una definida concepción de lo que es ser europeo. Esto por dos razones: una relativa a la transformación de la propia concepción de la identificación política con la propia comunidad de uno en los tiempos modernos, y la otra a la naturaleza mixta de la Unión Europea como una politeya multinivel...» (p. 29). Para Castiglione la identidad política contiene dos formas distintas: identificación y lealtad, cuya relación estudia en diferentes concepciones, remitiéndose él mismo a la paradoja que se expresa en la idea de «comunidad de extraños». «... la Unión Europea debe cultivar su identidad política ... en el más banal sentido de percepción creciente de los ciudadanos que la Unión contribuye a un orden fundamental (aunque multinivel) institucional y legal dentro del que pueden ejercer la libertad» (...) «la solución podría estar más en imaginar cómo un espacio político entrelazado puede necesitar sistemas entrelazados de confianza, solidaridad y lealtades: ninguna de las cuales necesita ser absoluta» (p. 51). La falta de puentes y los desajustes entre el proyecto de identidad europea de las elites y las preocupaciones de los ciudadanos (Díez Medrano), las líneas divisorias de clase en las pautas de cultura y de interacciones transnacionales (Fligstein) y las diferentes identificaciones y sus cambios producidos por la politización-despolitización de la integración europea (Kaelbe), estudiadas también en este libro, son muestras de los conflictos de esta comunidad de extraños.

57 Ibid., p. 227. 
rada, destacando la constitutividad sobre la causalidad e ideando y proponiendo ingeniosos indicadores.

«"La europeización de las identidades (nacionales)" se refiere a la medida en que las referencias a Europa y a la UE han sido incorporadas en las construcciones de identidad nacionales y otras. La europeización de las identidades es diferente de las "identidades europeas".$^{58} \mathrm{El}$ autor elabora conceptual y metodológicamente las identidades sociales desde el constructivismo: procesos de identificación social - parte del «yo» que pertenece a un más amplio «nosotros»-, identidades múltiples - separadas, cruzadas, anidadas y mezcladas -, contenido substantivo, límites de la comunidad y cambios de identidad. Después trata de medir la emergencia de las identidades europeizadas en los ciudadanos de a pié y en las elites y de explicarlas desde el constructivismo, que internaliza las identidades, intereses e instituciones y resalta los efectos constitutivos: «la evidencia es creciente que más de cincuenta años de integración europea han tenido efectos constitutivos en las identidades de la gente, conduciendo a la europeización de las identidades nacionales y a la emergencia de la identificación con Europa como una identidad secundaria. Sin embargo, esta europeización de identidades varía de unos a otros países (e incluso regiones) y está mitigada por los discursos y narrativas de la elite».59

De modo similar «una esfera pública europea transnacional emerge a través de la europeización de esferas públicas nacionales especialmente. Además, una esfera pública europea es un constructo social en el sentido que emerge en el proceso a través del cual los europeos se comprometen mutuamente y debaten asuntos de común interés europeo a través de las fronteras». ${ }^{60}$ Para la conceptualización de las esferas públicas transnacionales Risse toma de Habermas dos criterios normativos: a) que sea pública, es decir, abierta a la participación; y b) la posibilidad de cuestionar la autoridad pública, y desarrolla indicadores empíricamente observables de ellos para una esfera pública europea, que siguiendo a Habermas entiende como «una esfera política pública que posibilita a los ciudadanos posicionarse al mismo tiempo sobre los mismos tópicos de la misma relevancia». ${ }^{61}$ De la revisión de las evidencias empíricas concluye Risse que la visibilidad y semejanza de los ciclos de cuestiones han crecido en los decenios de 1990 y 2000 , mientras que los hallazgos respecto a los marcos de referencia y estructuras de significado son ambivalentes. Estamos viendo cómo va hacién-

58 RISSE, T., A Community of Europeans? Transnational Identities and Public Spheres, Cornell University Press, Ithaca, 2010, p. 9.

${ }^{59}$ Ibid., p. 101.

${ }^{60}$ Ibid., p. 11. Ver, también, p. 125.

${ }^{61}$ Ibid., p. 116. 
dose una comunidad de comunicación, aunque de modo desigual y a veces segmentado, y se reivindican los efectos constitutivos: «desde la perspectiva constructivista aquí adoptada... la emergencia de esferas públicas europeizadas y comunidades de comunicación constituye una politeya (polity) o refleja la emergencia de una politeya. Cuanto Europa más impacta en casa, más cuestiones europeas devienen politizadas y parte de una política doméstica europeizada y más emerge una "comunidad de extraños" como una politeya reflectora de si misma (Castiglione, 2009, parafraseando a Habermas 1996a)». ${ }^{62}$

En la parte III del libro se invierte la dirección: las anteriores variables dependientes - identidades y espacio público europeizados - se consideran variables independientes y se trata de analizar sus efectos en la construcción institucional europea. Advierte el autor que no deberíamos esperar efectos políticos directos de las identidades, ni explicaciones simples y que necesitamos distinguir los efectos constitutivos de los más directos causales. Pasa entonces a estudiar la opinión pública popular y los discursos de la elite tratando de examinar «las consecuencias de las identidades y esferas públicas europeizadas (o su falta) para la "profundización" de la UE, es decir, las cuestiones institucionales concernientes al alcance y nivel de la integración europea». ${ }^{63}$ Posteriormente se hace algo semejante respecto a la «ampliación» de la UE — «las luchas de identidad asumen un papel central»y a la democracia europea: «aunque algún grado de integración social y un sentido de comunidad son ciertamente condiciones para una politeya democrática, tal espíritu de comunidad no existe fuera del propio proceso político. Las identidades colectivas se construyen a si mismas constantemente y rectifican en el discurso político. La identidad europea no es excepción. Cuanto más cuestiones europeas de común interés son debatidas en las esferas públicas transnacional y europeizada, tanto más se está creando un sentido europeo de comunidad. Esto es lo que hemos observado en los pasados quince o veinte años». ${ }^{64}$

En las «Conclusiones: defendiendo una Europa moderna» Risse enfatiza la necesidad de una politización gradual para afrontar el déficit democrático, que a su juicio no es, sin embargo, primariamente resultado de la falta de identidades y de esferas públicas transnacionales europeizadas, sino más bien de la incongruencia entre el nivel UE, donde tiene lugar la elaboración de políticas - políticas sin política-, y los niveles nacionales, donde tiene lugar el juego político - política sin políticas-.

\footnotetext{
62 Ibid., pp. 173-174.

63 Ibid., p. 202.

${ }^{64}$ Ibid., pp. 229-230.
} 


\section{Reintroduciendo el poder}

Desde hacía algún tiempo se echaba en falta el tratamiento del poder en las aproximaciones constructivistas, aunque el constructivismo estratégico lo había afrontado de algún modo. ${ }^{65}$ Holtz y Von Dahlern lo han hecho recientemente. Sus hipótesis de trabajo son que el poder y la cultura se condicionan mutuamente y por tanto se necesita investigar hasta donde llega ese condicionamiento; que el intercambio funcional entre el poder y la cultura muestra rasgos constructivistas; además se investiga el fundamento que contribuye a la constitución de relaciones de poder o de mecanismos reguladores culturales. ${ }^{66} \mathrm{El}$ trabajo tiene un denso contenido teórico, aunque se analizan también con fines aclaratorios diversos casos prácticos. Se aboga por una aproximación interdisciplinar y cierta cautela ante las tendencias positivistas: «Las siguientes reflexiones se comprenden, por tanto, más bien como enriquecimiento funcional del discurso de la cultura en conexiones científico-políticas. La argumentación en conjunto no es estricta, sino que adrede se abre a senderos adyacentes para la iluminación de especiales aspectos teóricos y prácticos». ${ }^{67}$

Tras explorar las muy complejas y variadas conceptualizaciones de la(s) cultura(s) ${ }^{68}$ y del poder - «se trata a continuación de los influjos sobre el espacio social y las personas que en él se mueven»-, ${ }^{69}$ se interesan sobre todo por las conceptualizaciones que incluyen el substrato cultural y se adentran en el constructivismo, entendido como una meta-teoría, aplicable a diversos ámbitos, entre ellos el de las Relaciones Internacionales. Lo esencial del constructivismo es apuntar más allá de la realidad física, que por sí misma no dice mucho, asignándole significado para poder percibirla, orientarnos y ordenar la correspondiente fisis. ${ }^{70}$ Sin embargo, el constructivismo social, a diferencia del radical, no niega la realidad material, que está subordinada a la realidad interpretada, y en este sentido puede entenderse «como la ciencia del significado atribuido». Se puede categorizar tendencialmente el constructivismo por tres direcciones: a) la resocialización de la naturaleza y

65 SAURUGGER, S., op. cit., pp. 182-187.

${ }^{66}$ HOLTZ, A. y VON DAHLERN, N., Kultur, Macht, Politik. Konstruktivismus und die politische Beziehung von Kultur und Macht, Peter Lang, Frankfurt am Main, 2010, p. 18.

${ }^{67}$ Ibid., p. 20.

68 Ibid., p. 30: «La cultura se basa en la mediación e interacción sociales; actúa colectivamente y fundando identidad; se muestra material e inmaterialmente (lenguaje y significado); proporciona símbolos, crea significados (asignaciones), reduce la inseguridad como sistema de orden; actúa guiando la acción en la repetición performativa; asegura una continuidad en la historicidad; se transforma dinámicamente en el sentido de un proceso continuo».

${ }^{69}$ Ibid., p. 47.

70 Ibid., p. 100. 
la desnaturalización de lo social; b) la reidealización del mundo; y c) norma y cultura, y según Holtz y Von Dahlern es especialmente apto para el análisis de los intersecciones de cultura y poder. En las Relaciones Internacionales «siempre se debe preguntar qué comprensiones intersubjetivas son dominantes, por tanto tienen poder para formar estructuras e identidades», ${ }^{71}$ comprensiones intersubjetivas que a su vez son producidas dentro de esas estructuras.

La identidad es estudiada por Holtz y Von Dahlern como construcción cultural y mecanismo de poder, aclarando que entre las identidades (sobre todo grupales) y las relaciones de poder existe un determinado nexo, que radica en diversos intereses e ideas; el nacimiento de ideas es una tendencia humana genuina, basada en la capacidad humana para valorar hechos, y el esquema de valoración aplicado viene determinado por un sistema de coordenadas culturales para la orientación, que el ser humano hace suyo en las correspondientes situaciones. «Este nexo entre identidad y poder para la influencia del sistema de coordenadas culturales se puede transcribir como política de identidad». ${ }^{72}$

Después de analizar en los capítulos siguientes diversos caso de cultura en la práctica política concluyen Holtz y von Dahlern: «Fundamentalmente se ha mostrado que el análisis de situaciones políticas concretas mediante una aproximación interdisciplinar con un fuerte foco en el ámbito cultural siempre es enriquecedor...fundamentalmente debe subrayarse también una vez más que el marco conceptual constructivista solo puede desarrollar sentido en la aplicación concreta». ${ }^{73}$

Kratochvíl y colaboradores han tratado y puesto de manifiesto con sensibilidad y sutileza las relaciones de poder en Europa llevando a cabo finos análisis empíricos desde el constructivismo. En el continuado debate entre constructivistas y racionalistas critican los intentos de acercar posiciones tanto de «los constructores de puentes» como de «los ópticos» con sus «lentes analíticas», porque ambos mantienen separadas las dos aproximaciones, que sin embargo es posible combinar, moverse de una a otra o emplearlas simultáneamente. Elaboran una tipología de cuatro combinaciones de constructivismo y racionalismo para el estudio de las relaciones UE-participantes externos, que aplican al estudio de la política europea de vecindad (Ucrania, Moldova y Georgia) y detectan en estos países el cambio desde la política de identidad (deseo de unirse a Europa) a la política de pragmatismo (obtención de beneficios), explicando este giro pragmático por la influencia del actor más poderoso - la Comisión Europea - que «ha sido

${ }^{71}$ Ibid., p. 112.
${ }^{72}$ Ibid., p. 144.
${ }^{73}$ Ibid., p. 252. 
capaz no solo de influir la orientación normativa de los participantes más débiles, sino también de inducir un cambio desde la política basada normativamente a la aproximación conducida por el interés».74

En un artículo posterior Kratochvíl y otros colaboradores de la Universidad de Praga han explorado el poder de la UE para enmarcar los debates sobre acción exterior de los Estados miembros: ¿se ve a la UE como un actor mayor en las relaciones exteriores de los Estados Miembros individuales? Llevan a cabo un análisis del discurso de algunos de los periódicos más importantes de Alemania, Francia y el Reino Unido en la cobertura del caso de Ucrania (2002-2007), que confirma la percepción de la UE como el principal actor en la mayoría de los 1901 artículos examinados, concluyéndose «que la UE está fuertemente presente en el discurso público sobre política exterior de estos países y que frecuentemente ocupa un lugar incluso más preeminente que los Estados Miembros de la UE individualmente». ${ }^{75}$

\section{Algunas reflexiones}

A finales del siglo Xx el constructivismo cuestionó la corriente dominante en las Relaciones Internacionales y en la política exterior de los Estados Unidos, basadas tradicionalmente en el individualismo racionalista y el poder realista y aportó una nueva visión. No supuso, sin embargo, una novedad semejante en las aproximaciones y teorías de la Unión Europea y en la visión política internacional de ésta. No es que Europa históricamente no hubiese teorizado y practicado el egoísmo, el poder y las crudas ambiciones entre Estados soberanos - ahí están el modelo westfaliano, el nacionalismo y el colonialismo-, pero sus catastróficas consecuencias impulsaron después de la II Guerra Mundial cierta crítica teórica y sobre todo un nuevo proyecto político: las Comunidades Europeas, al que no eran aplicables sin correcciones fundamentales el puro realismo materialista y el individualismo egoísta del racionalismo. Así lo detectaron muy pronto incluso algunos de los primeros grandes teóricos norteamericanos o euro-norteamericanos de la integración europea como Haas, Deutsch y Stanley Hoffmann.

Los buenos tiempos de la CE/UE, en los que disfrutó de paz, prosperidad, democracia y Estado de Bienestar, generaron el llamado consenso

74 KRATOCHVÍL, P. y TULMETS, E., «Constructivism and Rationalism as Analytical Lenses: The Case of the European Neighbourhood Policy», Politics in Central Europe, 6 (June 2010) 1, p. 37.

75 KRATOCHVÍL, P.; CIBUlKOVÁ, P. y BENÍK, M., «The EU as a "Framing Actor": Reflections on Media Debates about EU Foreign Policy», Journal of Common Market Studies, 2011, Vol. 49, N. ${ }^{\circ}$ 2, p. 408. 
permisivo y un bajo nivel de politización de una integración europea sin grandes exigencias ni mayores costes para los ciudadanos. Sin embargo, a finales del siglo XX y comienzos del XXI, profundos y vertiginosos cambios científicos y tecnológicos, económicos y financieros, sociales e internacionales trajeron enormes desafíos para la Unión Europea y pusieron de manifiesto sus debilidades e insuficiencias para competir en un mundo globalizado con poderosos actores emergentes y para avanzar hacia una mayor unión política. La encrucijada se formuló con claridad diáfana: avanzar decididamente o caer en la irrelevancia exterior y la desafección interior.

En el último decenio, la deriva europea ha sido crecientemente intergubernamental y realista y además con poderosos rebrotes nacionalistas, junto con el crudo predominio de los «mercados», la erosión del Estado de Bienestar y el incremento de las desigualdades sociales, la pérdida de profundidad y vigor de la democracia y la hegemonía del pensamiento natural-tecnocrático. Es necesario reivindicar hoy la deconstrucción de ese constructo anticomunitario y la reconstrucción actualizada de las ideas y valores que dieron origen y fundamentan las Comunidades Europeas/Unión Europea y son constitutivas de ella. Europa en crisis y en cambio puede y debe engendrar nuevas ideas, identidades e intereses, constitutivos de ciudadanos europeos capaces de afrontar el desafío de construir una Europa renovada en un mundo globalizado.

Las relaciones interestatales y de poder probablemente van a seguir siendo todavía predominantes en las formas institucionales de los próximos años, pero a fin de que el proyecto europeo sobreviva e influya en la configuración de la globalización de acuerdo con nuestras ideas, valores, identidades e intereses, y hacerlo de modo democrático y participativo, es necesario reaccionar ya. Algunos de los aportes constructivistas que hemos expuesto pueden ayudarnos: ideas compartidas, identidades e intereses de los actores y su relación mutuamente constitutiva con las estructuras ideales, sociales e institucionales; la posibilidad del cambio; la interacción entre comunidad política y formación de la identidad; el proceso en el que endógenamente se van haciendo las identidades e intereses; socialización y aprendizaje; europeización de las identidades y de las esferas públicas por un lado e identidad y esfera pública europeizadas por otro; europeización y deseuropeización; poder y cultura; relaciones de poder y mecanismos culturales reguladores; comprensiones intersubjetivas dominantes configuradoras de identidades y estructuras.

Las estructuras y el poder suelen ser determinantes en el corto plazo; en el largo, las ideas y las culturas. Constitutividad mutua de estructuras y agentes, agentes y estructuras, de poder y cultura, cultura y poder, que el constructivismo enfatiza. Hay que realizar análisis empíricos en situaciones concretas y aprovechar las ventanas de oportunidad para la acción 
apropiada. La actitud, la teorización y la acción constructivistas de los actores esconden relevantes potencialidades para la humanización y democratización de las estructuras y el poder y para la construcción de una Europa política democrática en un mundo en proceso de creciente globalización. Es necesario activarlas frente a inmensos intereses y poderes en otras direcciones. 